\title{
A Response to "Assessing Medical Students' Knowledge of Genetics: Basis for Improving Genetics Curriculum for Future Clinical Practice" [Letter]
}

\author{
Nishaanth Dalavaye (D) \\ Department of Medicine, Imperial College London, London, UK \\ Correspondence: Nishaanth Dalavaye, Imperial College School of Medicine, Imperial College London, South Kensington Campus, Sir Alexander \\ Fleming Building, London, UK, Email nish.dalavaye2I@imperial.ac.uk
}

\section{Dear editor}

I read with interest the paper by Alotaibi and Cordero investigating the knowledge of medical students in the field of clinical genetics, particularly as this is relevant to myself as a fourth-year medical student. ${ }^{1}$ The authors have evaluated that clinical genetics knowledge is generally insufficient amongst fourth-year medical students.

Multiple-choice questions (MCQs) are the most commonly used tool to assess knowledge in medical education. However, MCQs have limitations as an assessment tool, and they can give a false impression of a students' competence. ${ }^{2}$ The authors may have benefitted from using very short-answer questions (VSAs) as an alternative to MCQs. Recent evidence suggests that VSAs provide a more authentic assessment of students' abilities compared to MCQs, as they can identify cognitive errors more readily and potentially better quantify where teaching needs to be targeted. ${ }^{3}$ Moreover, after inspecting the example Genetics MCQs included in the study, it appears that certain MCQs are mainly testing direct, factual knowledge recall with less emphasis on testing more complex clinical reasoning and problem-solving ability. It is therefore unsurprising that the second-year students performed better than the fourth-year students in wider knowledge domains, considering they likely revised the directly pertinent resources in closer proximity to the assessment and could recall facts with greater clarity. The reduced ability of students in later years of medical school to recall factual knowledge has been previously demonstrated. ${ }^{4}$

The fact that $87.8 \%$ of second-year students responded that their genetics knowledge was insufficient for clinical practice is surprising, considering they had recently received all the formal genetics teaching in the curriculum. However, the value of asking pre-clinical students to self-assess their preparedness for future clinical practice is debatable, considering they have not yet been exposed to the clinical environment and are unlikely to be fully aware of the required clinical genetics knowledge of competent physicians. A sub-group analysis of the fourth-year student cohort including analysis of factors that affected their responses to preparedness would be valuable. The COVID-19 pandemic will indubitably have affected the students' learning opportunities, so its impact should also be factored into the sub-group analysis.

The small sample size and limitation to a single medical school makes it difficult to ascertain the generalisability of the conclusions to the wider medical student population. However, as discussed by the authors, the findings are backed by existing literature. Clinical genetics is a rapidly evolving field and it is imperative that knowledge gaps are addressed from an undergraduate level. In the United Kingdom (UK), one way this could potentially be addressed is through the upcoming United Kingdom Medical Licensing Assessment (UKMLA); a summative licensing assessment taken by all future UK medical students. In the current UKMLA content map, there is a separate domain of professional knowledge titled "Genetics and genomics". 5 The high-stakes nature of this exam will therefore hopefully encourage increased representation of genetics in the curriculum and motivate students to optimise their knowledge. 


\section{Disclosure}

The author reports no conflicts of interest in this communication.

\section{References}

1. Alotaibi AA, Cordero MAW. Assessing medical students' knowledge of genetics: basis for improving genetics curriculum for future clinical practice. Adv Med Educ Pract. 2021;12:1521-1530. doi:10.2147/AMEP.S337756

2. Bird JB, Olvet DM, Willey JM, Brenner J. Patients don't come with multiple choice options: essay-based assessment in UME. Med Educ Online. 2019;24(1):1649959. doi:10.1080/10872981.2019.1649959

3. Sam AH, Westacott R, Gurnell M, Wilson R, Meeran K, Brown C. Comparing single-best-answer and very-short-answer questions for the assessment of applied medical knowledge in 20 UK medical schools: cross-sectional study. BMJ Open. 2019;9(9):e032550. doi:10.1136/bmjopen2019-032550

4. D'Eon MF. Knowledge loss of medical students on first year basic science courses at the university of Saskatchewan. BMC Med Educ. 2006;6(1):5.

5. MLA content map [Internet]. London: General Medical Council; 2021 [cited January 3, 2022]. Available from: https://www.gmc-uk.org/education/ medical-licensing-assessment/mla-content-map. Accessed January 28, 2022.

Dove Medical Press encourages responsible, free and frank academic debate. The content of the Advances in Medical Education and Practice 'letters to the editor' section does not necessarily represent the views of Dove Medical Press, its officers, agents, employees, related entities or the Advances in Medical Education and Practice editors. While all reasonable steps have been taken to confirm the content of each letter, Dove Medical Press accepts no liability in respect of the content of any letter, nor is it responsible for the content and accuracy of any letter to the editor.

Advances in Medical Education and Practice

Dovepress

\section{Publish your work in this journal}

Advances in Medical Education and Practice is an international, peer-reviewed, open access journal that aims to present and publish research on Medical Education covering medical, dental, nursing and allied health care professional education. The journal covers undergraduate education, postgraduate training and continuing medical education including emerging trends and innovative models linking education, research, and health care services. The manuscript management system is completely online and includes a very quick and fair peer-review system. Visit http://www.dovepress.com/testimonials.php to read real quotes from published authors.

Submit your manuscript here: http://www.dovepress.com/advances-in-medical-education-and-practice-journal 